Recibido: 03/abril/2017 Aprobado: 29/mayo/2017

ARTÍCULO ORIGINAL

\title{
Screening fitoquímico y evaluación de la actividad antimicrobiana de: Catharanthus Roseus (1.) G. Don, Justicia Pectoralis Jacq. y Scoparia Dulcis L.
}

Screnning photochemical and evaluation of antimicrobial activity of Catarantus Roseus (I.)

G. Don, Justicia Pectoralis Jacq. and Escoparia Dulcis

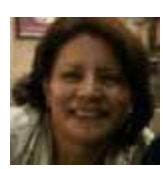

Balseca Mata Rafaela Dolores

Bioquímica Farmacéutica Licenciada en Ciencias Naturales y del Ambiente Biología y Química Especialista en Fitoquímica y Biología Molecular Colegio Municipal Sebastián de Benalcázar. Docente Facultad de

Ciencias Químicas Universidad Central del Ecuador

e-mail: rafa_balseca@hotmail.com

\section{Resumen}

El presente trabajo tiene como propósito; realizar el screening fitoquímico, mediante el método descrito por CIULEI y determinar la acción antimicrobiana de: Scoparia dulcis L., Justicia pectoralis Jacq, y Catharanthus roseus (L.) G. Don, mediante el método pro-puesto por Mitscher 1988. Este método se fundamenta en la susceptibilidad bacteriana, medida in vitro. Consiste en utilizar el extracto de interés, frente a los microorganismos de elección, en medio de agar y condiciones de completa asepsia. Catharanthus roseus (L.) G. Don es la especie que mayor cantidad de alcaloides presenta, seguida de Justicia pectoralis Jacq. Y a continuación Scoparia dulcis L. esta última es la que mayor cantidad de Taninos y Glicósidos Cardiotónicos presenta seguida de Catha-ranthus roseus (L.) G Don y Justicia pectoralis Jacq. que presentan similitud en el contenido de Taninos y Glicósidos Cardiotónicos. En cuanto a los Esteroides, las 3 especies en estudio presentan igual cantidad y únicamente Justicia pectoralis Jacq. contiene una ligera cantidad de Flavonoides. El extracto crudo estandarizado de Scoparia dulcis L. presenta actividad antibiótica (acción bacteriostática), sobre Pseudomona aeruginosa desde una concentración de $62.55 \mathrm{ug} / \mathrm{ml}$ siendo esta la concentración mínima inhibitoria CMI. Así como también presenta actividad antifúngica con poder fungicida con respecto a la levadura Candida albicans a una concentración de $31.25 \mathrm{ug} / \mathrm{ml}$, siendo ésta la CMI.

Palabras Claves: scoparia dulcis 1.; justicia pectoralis jacq.; catharanthus roseus (1.) g. don; screening fitoquímico y acción anti-microbiana

Abstract: The present work purpose is to determinate the antimicrobial action or the Scoparia dulcis L., Justicia pectoralis Jacq., and Ca-tharanthus roseus (L.) G. Don, through the method proposed by Mitscher 1988. This method is based in the bacterial susceptibility measured in vitro. It consists on using the interest extract with the microorganisms of election in agar environment and complete asepsis conditions. Catharanthus roseus (L.) $G$. Don is the species that presents the greatest number of alkaloids, followed by Justicia pectoralis Jacq. and Scoparia dulcis L, which has the highest number of Tannins and Cardiotonic Glycosides and the next, is Catharanthus roseus (L.) G. Don and Justicia pectoralis Jacq. Which present a similar content of Tannins and Cardiotonic Glycosides? Regarding to the steroids the 3 studied species present a similar quantity and only Justicia pectoralis Jacq. has light quantity of Flavonoids. The raw standardized extract of Scoparia dulcis L. shows antibiotic action (bacteriostatic action), about Pseudomona aeruginosa from a concentration of $62.55 \mathrm{ug} / \mathrm{ml}$, this one is the minimum inhibitory concentration CMI. It also presents antibiotic activity with fungicide power in the microorganism Candida albicans in a concentration of $31.25 \mathrm{ug} / \mathrm{ml}$; this is the CMI.

Key words: scoparia dulcis l; justicia pectoralis jacq. and catharanthus roseus (l.) g. don; screening fitoquimico and antimicrobial action 


\section{Introducción}

La alta incidencia de enfermedades infecciosas y el hecho de que, el hombre está ligado a su medio ambiente, en el que en muchas ocasiones la enfermedad es tratada con medicina natural, nos hace pensar en la alternativa de encontrar principios activos con efectividad en el tratamiento de infecciones bacterianas, estudiando la capacidad de nuestras plantas como fuente medicinal y aplicar este conocimiento en forma racional (Villacres, 1995)

El hecho de que no existe un sistema de control y vigilancia efectivo, que garantice la calidad de los fitofárma$\cos$, que muchas de las veces son envasados en forma directa, del cultivo al frasco sin haber sido comprobado el efecto terapéutico señalado, lo que conlleva a que los pacientes tomen únicamente placebos que pueden agravar su cuadro clínico, por la falta de investigación de los principios activos de nuestra pródiga biodiversidad, en plantas medicinales. El propósito es dar un sustento científico al uso etnomédico y por ende, reactivar la economía del país en este sector.

Con la presencia de nuevos microorganismos y levaduras resistentes a los antimicrobianos y antimicóticos, respectivamente, y utilizados de manera común, surge la necesidad de encontrar nuevos antimicrobianos y antimicóti$\cos$, que ayuden a solucionar este problema de salud.

Nos atrevemos a predecir que, a través de esta vía se podrán controlar Pandemias "que hoy constituyen verdaderos azotes para la humanidad como el cáncer y el SIDA", de ahí la trascendencia del estudio de estas 3 plantas que fueron domesticadas en el centro científico de Río Palenque: Scoparia dulcis L. Justicia pectoralis Jacq y Catharanthus roseus (L.) G. Don, en las que se realizó el screening fitoquímico y se determinó su actividad antimicrobiana y antifúngica como un aporte para el conocimiento de las bondades de estas 3 plantas.

Teniendo como base el uso etnomédico, así como bibliográfico, con el propósito de darles el respectivo sustento científico.

En nuestro país, en la provincia de los Ríos, el uso etnomédico de Scoparia dulcis L., Justicia pectoralis Jacq. Catharanthus roseus (L.) G. Don. justifica su investigación en el campo científico, con una serie de procesos y actividades que dan el sustento científico a dicho uso, esto motivó el desarrollo del presente proyecto, con el objetivo de determinar la posible acción antimicrobiana de las tres especies vegetales estudiadas.

Como ejemplos citaré el uso de Scoparia dulcis L. de la cual el producto de su cocimiento se utiliza como

cicatrizante, la infusión para las erupciones de la piel, antiinflamatorio en tumores e hinchazones.

Justicia pectoralis Jacq. La infusión para contrarrestar la tos y afecciones de las vías respiratorias.

Las hipótesis planteadas son:

Ho. Las tres plantas de estudio tienen igual composición química.

Ha. Las tres plantas de estudio tienen diferente composición química.

1Ho. Las tres especies vegetales motivo de estudio tienen similar actividad antibacteriana (+) y (-). sobre gérmenes Gram

1Ha. Las tres especies vegetales en estudio tienen diferente actividad bacteriana sobre gérmenes Gram $(+)$ y (-).

En el presente trabajo de investigación se planteó como objetivo general evaluar la efectividad antibacteriana de: Scoparia dulcis L, Justicia pectoralis Jacq. Y Catharanthus roseus (L.) G. Don., procedentes de la estación científica de Río Palenque.

Las tres especies vegetales fueron cultivadas en el centro científico de Río Palenque.

\section{Fundamentos Botánicos}

Tabla 1. Clasificación Taxonómica de las 3 plantas

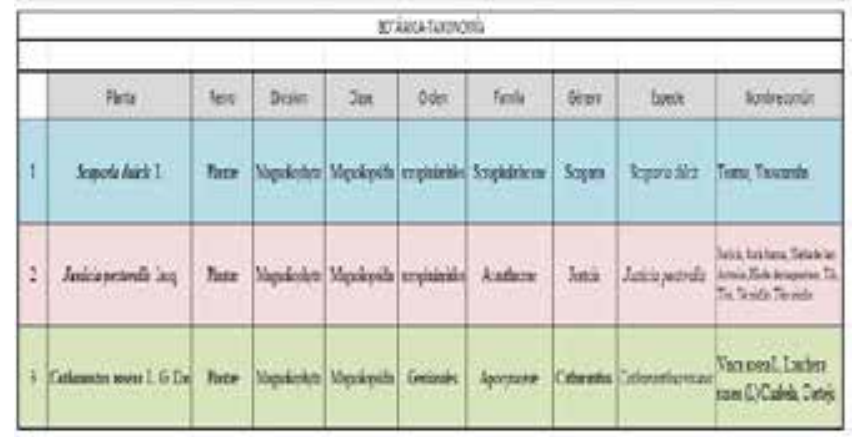

Fuente: Herbario Nacional

\section{Scoparia dulcis. Origen.}

Es una planta nativa de América, con una distribución en el mundo tropical.

En Brasil ocupa la mayor parte del territorio, muy raramente aparece en concentraciones mayores, siendo infestante en pastizales y cultivos, especialmente perennes como el café.

\section{Justicia pectoralis Jacq. Origen.}

Justicia pectoralis Jacq. es nativa de los trópicos de América, se encuentra tanto en las Antillas como en la zona continental de América.

\section{Catharanthus roseus (L.) G. Don. Origen.}

Es una planta natural de Madagascar (África sur oriental), actualmente extendida por regiones tropi-cales de todo el mundo. 


\section{Materiales y métodos}

\section{Población}

La población de estudio se estableció de la siguiente manera: 15000 plantas de Scoparia dulcis L. 15000 plantas de Justicia pectoralis Jacq. Y 15000 plantas de Catharanthus roseus (L.) G. Don.

\section{Muestra.}

De cada una de las especies vegetales en estudio, se nos proporcionó $1000 \mathrm{~g}$ de planta molida, hasta un mm de diámetro de partícula para realizar el estudio.

\section{Materiales}

Embudos grandes de filtración, Erlenmeyers. Probetas, Balanza Analítica, Soxhlet, Rotavapor, Estufa de aire circulante, liofilizador, cajas Petri, micro pipetas, Cámara de Flujo Laminar, autoclave, asas de platino, mechero Bunsen.

\section{Métodos Específicos de Análisis}

Métodos Botánicos: Para identificar y clasificar las especies vegetales se utiliza el método de Cronquis y el Método de Comparación con Voucher, siendo este último el utilizado en la Estación Científica de Río Palenque.

\section{Métodos Químicos}

Preparación de los Extractos Etanólicos Estandarizados. Los extractos fueron preparados por medio de una maceración seguida de una percolación.

Maceración Pesamos $100 \mathrm{~g}$ de material seco, lo colocamos en el embudo de vidrio, al que previamente se le puso gasa, algodón y papel filtro agujereado, armando un percolador. Se procedió a humedecer con $10 \mathrm{ml}$ de etanol de $75 \%$ por $15 \mathrm{~min}$, al cabo de los cuales añadimos más etanol hasta completar $1000 \mathrm{ml}$, y lo dejamos macerando por $24 \mathrm{~h}$. Posteriormente se procedió a recolectar el percolado, se abrió la llave inferior y se permitió salir el menstruo a la velocidad de 3 a $5 \mathrm{ml} /$ min; se recogió un volumen de percolado $85 \mathrm{ml}$ y se conserva aparte en el refrigerador, en otro frasco colector, se continúa el proceso hasta agotar el percolado.

La segunda fracción de lixiviado se concentró a presión reducida a una temperatura de 40 a $450 \mathrm{o}$ en el rota vapor BUCHI hasta consistencia de extracto blando $(15 \mathrm{ml})$ y que, reunido con la primera fracción separada y refrigerada, completan las 100 partes correspondientes del extracto final programado; este extracto se deja reposar por 4 días a una temperatura de 10oC. A continuación se liofilizó hasta extracto seco.

\section{Screening o tamizaje fitoquímico}

El análisis o screening fitoquímico s e e fectuó, e n e l laboratorio del centro Científico de Río Palenque, actuando sobre los extractos de las tres especies vegetales.
El método utilizado, fue el descrito por CIULEI (Nicolai Sharapin, 2000) que ofrece mayor reproducibilidad siendo de más fácil ejecución. El método permite determinar la presencia de los principales grupos de compuestos químicos, tanto libres, como en la forma de glicósidos, por medio del desarrollo de reacciones de color y precipitados. (Nicolai Sharapin, 2000)

El tamizaje o "screening" fitoquímico es una de las etapas iniciales de la investigación Fitoquímica, que permite determinar cualitativamente los principales grupos químicos, presentes en una planta y, a partir de allí, orientar la extracción y/o fraccionamiento de los extractos para el aislamiento de los grupos de mayor interés. (Nicolai Sharapin, 2000)

El tamizaje fitoquímico debe permitir la evaluación rápida, con reacciones sensibles, reproducibles y de bajo costo. Los resultados del tamizaje constituyen únicamente una orientación y deben interpretarse en conjunto con el resultado del screening farmacológico. (Nicolai Sharapin, 2000)

La cantidad de material vegetal que se empleó para hacer las pruebas fue de $200 \mathrm{~g}$.

\section{Marcha Sistémica}

La extracción se efectúa utilizando la droga seca y molida con la ayuda del éter, empleando para el efecto un Soxhlet, posteriormente el residuo se seca y se extrae con alcohol. Finalmente, la droga se extrae con agua, bajo reflujo. Los extractos etéreo, alcohólico y acuoso se someten a una secuencia de pruebas químicas- (Nicolai Sharapin, 2000)

\section{Actividad antimicrobiana}

Tratamiento preliminar de las muestras vegetales Las plantas para la investigación microbiológica, fueron secadas en aire circulante entre 40-50oC.

Las plantas una vez secas fueron molidas, tamizadas y homogenizadas hasta un tamaño de $1 \mathrm{~mm}$. de partícula. A continuación se estandariza el extracto etanólico crudo total a una concentración de $1 \mathrm{~g} / \mathrm{mL}$. por medio del método de maceración, seguido de una percolación, utilizando como menstruo alcohol de 75oGL. finalmente son sometidos al proceso de secado por el método de liofilización, para obtener los extractos secos correspondientes.

La efectividad antimicrobiana de: Scoparia dulcis L. Justicia pectoralis Jacq. y Catharanthus roseus (L.) G. Don. se determinó sobre gérmenes Gram (+) o Gram (-) así como también sobre la levadura Candida albicans

El método que se escogió para la determinación de la actividad antimicrobiana de las tres plantas fue el método de Mitscher, más conocido como el método de dilución. (CYTED, 1995) 


\section{Metodología}

Preparación de Muestras para el ensayo antimicrobiano

Dilución de Extractos crudos. Pesar con precisión 20 $\mathrm{mg}$ de extracto crudo y disolver en un vial con $0,2 \mathrm{~mL}$ de Dimetil Sulfo Oxido DMSO. Una porción de esta disolución $(100 \mathrm{uL})$ se pipetea en una caja Petri marcada. Esto debe realizarse asépticamente.

Después que las cajas se prepararon, se dejó en refrigeración. El residuo (remanente) de los tubos preparados se trató de la misma manera.

Cuando los extractos muestran actividad a este nivel, se llevó a cabo un segundo experimento.

Para este ensayo, se pesó $20 \mathrm{mg}$ del extracto y se disolvió en un volumen apropiado de DMSO (por ej., 20 mg en $200 \mu \mathrm{L}$ de disolvente).

Como antes, se pipetea $100 \mu \mathrm{L}$ de esta disolución en una caja Petri guardando condiciones de asepsia. El remanente de esta disolución $(0.1 \mathrm{~mL})$ se diluyó en un vial estéril con DMSO. Esto da origen a una segunda disolución que contiene $1000 \mu \mathrm{g} / 100 \mu \mathrm{L}(1 \mathrm{mg} / 0.1 \mathrm{~mL})$. Luego se continúa con las diluciones hasta obtener concentraciones de 500. 250, 125, 62.5, 31.25 $\mu \mathrm{g} / 100 \mu \mathrm{L}$.

\section{Screening antibacteriano}

Método de Mitscher (CYTED, 1995); procedemos a colocar el extracto en $\mu$ l. en la caja de Petri en la cámara de flujo laminar, se deja evaporar el solvente, y se añade el agar, "Trypticase Soy Agar" TSA, se agita y se deja solidificar.

Activación de cepas bacterianas; procedemos a preparar tubos con "Trypticase Soy Broth" TSB en el cual inoculamos una asada de suspensión bacteriana.

A continuación, tomamos una asada de bacterias y procedemos a sembrarlas por rayado, en las cajas con divisiones en número de 8 , siguiendo la plantilla.

Se incuban a $37 \mathrm{oC}$ por $24 \mathrm{~h}$.

Se enumeran las cepas bacterianas en el siguiente orden:

1. Salmonella typhimuriun ATC No 14028 2. Escherichia coli ATCC No11775
3. Proteus SPP
4. Klebsiella SPP
5. Staphylococcus aureus, ATCC No25923.
6. Pseudomona aeruginosa SPP

\section{Candida albicans SPP.}

Stock de sulfato de estreptomicina. Se preparó un stock de soluciones de sulfato de estreptomicina como patrón de reacción positiva.
Se pesó exactamente 100mg de sulfato de estreptomicina, y se diluyó en $10 \mathrm{ml}$. de agua destilada estéril por ser soluble en dicho solvente. Esta disolución contiene $1000 \mu \mathrm{g} / 100 \mu \mathrm{L}(1 \mathrm{mg} / 0.1 \mathrm{~mL})$.

Para las diluciones con el antibiótico se procede igual que en las preparaciones de los extractos, obteniendo una concentración final de $500 \mathrm{ug} / \mathrm{ml} .250 \mathrm{ug} / \mathrm{ml}$, $125 \mathrm{ug} / \mathrm{ml}, 62.5 \mathrm{ug} / \mathrm{ml}, 31,25 \mathrm{ug} / \mathrm{ml}$.

Estas soluciones se colocaron en cajas Petri, 100ul de cada una. en $10 \mathrm{ml}$ de "Trypticase Soy Agar" TSA exactamente medido para tener una concentración final de $1 / 10 \mathrm{ml}$.

Las cajas con estreptomicina así preparadas, son estables, guardadas en refrigeración, al igual que la solución patrón y pueden ser utilizadas en cada ensayo como control positivo.

Preparación de los medios de cultivo "Trypticase Soy Agar" (TSA) se disolvieron 40g de TSA en un litro de agua destilada, esta cantidad es suficiente para aproximadamente 100 cajas.

Se hirvió el agua, se añadió el agar, se calentó la suspensión hasta que se logró disolución clara; luego, esta disolución se transfirió a tubos con tapa (10mL/tubo) $\mathrm{y}$ a un erlenmeyer, y posteriormente se esterilizaron en autoclave por 15 minutos a $121 \mathrm{oC}$.

“Trypticase Soy Broth" (TSB) Se disolvió 30g de TSB en un litro de agua destilada, se hirvió el agua; luego, se agregó al medio, y se calentó hasta obtener una disolución clara. Con una jeringa automática se transfirieron $10 \mathrm{~mL}$. de TSB a los erlenmeyers individuales de $25 \mathrm{~mL}$. Estos se esterilizaron en autoclave a $121 \mathrm{oC}$ por 15 minutos.

Nota: Podrá emplearse el medio Agar Muller- Hinton, a cambio de los medios anteriores.

Se utilizaron estos medios porque favorecen el crecimiento de microorganismos fastidiosos (Exigentes en sus requerimientos) siendo estos aerobios y anaerobios.

Mantenimiento de microorganismos. Los microorganismos fueron cepas de trabajo donados por el Laboratorio de Microbiología de la Facultad de Ciencias Químicas de la Universidad Central.

En los tubos de agar inclinados "Trypticase Soy Agar" (TSA) se inocula cada tres semanas los microorganismos. La siembra se efectuó por picadura y se incubó por 24 horas para su crecimiento a $37 \mathrm{oC}$, con identificación y la correspondiente rotulación.

Es importante siempre identificar cada uno y anotar la fecha de siembra. 
Preparación de disolución salina Se preparó disolución salina al $0.9 \%$. Se esterilizó en autoclave a 121 oC por 15 minutos.

Preparación de las cajas. Después de que se esterilizó el Agar, se dejó enfriar aproximadamente a 55 oC. Asépticamente, se añaden $10 \mathrm{~mL}$ de Agar a cada caja Petri sobre el antibiótico o el extracto respectivamente.

Luego, se agitó suavemente la mezcla para homogenizar. Cuando el Agar se solidificó, las cajas se voltearon y se mantuvieron a temperatura ambiente toda la noche.

Preparación de suspensiones con microorganismos. El medio ideal para el crecimiento de los microorganismos es el de Trypticase Soy Broth (líquido), previamente esterilizado con vapor de agua.

Se prepararon sendos tubos de ensayo para cada microorganismo con $10 \mathrm{ml}$ de TSB exactamente medido y se inoculó dos asadas tomadas de los tubos de TSA, se incuba a 37o por 24 horas, luego de las cuales, los medios deben estar visiblemente turbios (crecimiento bacteriano positivo).

Con la finalidad de tener la misma isotonicidad de los microorganismos en las cajas de los extractos, es importante diluir con la solución salina estéril, antes de ser sembrados.

La solución se detalla así:

Staphylococcus aureus ATCC 25923 100ul susp. /10ml sol. Salina

Escherichia coli ATCC 11775 100ul susp. /10ml sol. Salina

Salmonella typhimurium ATCC 14028 100ul susp. $/ 10 \mathrm{ml}$ sol. Salina

Proteus vulgaris SPP $100 \mathrm{ul}$ susp./10ml sol. Salina

Klebsiella SPP

100ul susp./10ml sol. Salina

Pseudomona aeruginosa PP 1ul susp. /10ml sol. Salina Candida albicans SPP 1 ul susp. $/ 10 \mathrm{ml}$ sol. Salina

Rayado de los microorganismos. Antes de iniciar la siembra de los microorganismos en las cajas Petri, se debe tomar en cuenta lo siguiente:

Identificar claramente los tubos. Se debe tener las cajas completamente libres de humedad.

Las cajas que presenten contaminación deben ser desechadas.

El asa de inoculación debe ser flameada antes y después de usarla.

Nunca se debe topar con el asa caliente la superficie del medio, ya que puede ser la causa de la formación de aerosoles contaminantes o se puede inhibir los microorganismos del inóculo.
Se tomó de las suspensiones de microorganismos diluidos con solución salina una asada y se sembró en los platos Petri en forma radial, siguiendo una plantilla marcada, para cada uno de ellos.

Cuidando no topar una raya con otra, es decir un microorganismo con otro, para evitar contaminación.

Una vez terminado el rayado, se incubaron las cajas por 48 horas a $37 \mathrm{oC}$.

Se preparó un plato Petri con "Trypticase Soy Agar" TSA puro, como control negativo del ensayo, en el que se verificó el crecimiento de todos los microorganismos.

Criterio de Evaluación Antimicrobiano. Existe actividad antimicrobiana de los extractos cuando no hay crecimiento visible en las líneas de siembra.

La actividad antibacteriana de los extractos de plantas se verifica a los 4 días de crecimiento y en los que no hubo, 1 día más.

Para los resultados se deben considerar los controles positivos y negativos.

Concentración mínima inhibitoria. Como los extractos muestran actividad antibacterial, se realizó la prueba con concentraciones que varían en forma decreciente, por Ej.: $500 \mathrm{ug} / \mathrm{ml}, 250 \mathrm{ug} / \mathrm{ml}, 125 \mathrm{ug} / \mathrm{ml}, 62.5 \mathrm{ug} /$ $\mathrm{ml}, 32.25 \mathrm{ug} / \mathrm{ml}$; para definir la concentración mínima inhibitoria (CMI), como la menor concentración en la cual existe actividad antimicrobiana es decir la concentración a la cual no hay crecimiento bacteriano.

Concentración mínima bactericida (CMB) es la mínima concentración a la cual son eliminadas el $99.9 \%$ de bacterias del inóculo. (RUSSELLS, 2004)

Cepas Bacterianas utilizadas. Tenemos cepas de referencia que vienen en polvo y son liofilizadas y cepas de trabajo que son identificadas y preparadas previamente. Para nuestro estudio utilizamos cepas de trabajo donadas por el laboratorio de microbiología de la Universidad Central, cuyo origen es el siguiente: Staphylococcus aureus ATCC No. 25923, Klebsiella pneumoniae spp responsable de las enfermedades del tracto respiratorio superior, Escherichia coli ATCC No. 11765, Salmonella typhimurium ATCC NO. 14028 responsables de las enfermedades del tracto gastrointestinal, Proteus spp, por presentar resistencia a los agentes antimicrobianos, Pseudomona aeruginosa spp patógena oportunista y la levadura Candida albicans spp responsable de la candidiasis.

\section{Resultados}

\section{Screening o tamizaje fitoquímico cualitativo}

El análisis o screening fitoquímico se efectuó en el laboratorio del Centro Científico de Río Palenque; en los extractos de las tres especies vegetales: Scoparia dul- 
cis L. Justicia pectoralis Jacq. y Catharanthus roseus (L.) G. Don. Se encontró en todas ellas: Alcaloides y esteroides en mayor proporción, taninos y glicósidos cardiotónicos en menor proporción y únicamente en la especie botánica justicia pectoralis Jacq, además de los citados, una ligera presencia de flavonoides.

\section{Resultados de la Actividad Antimicrobiana.}

a) El extracto crudo estandarizado de Scoparia dulcis L. presenta actividad antibiótica en el cultivo de Pseudomona aeruginosa ya que el microorganismo es morfológicamente alterado, no muestra su pigmento verde característico a una concentración de $62.5 \mu \mathrm{g} / \mathrm{ml}$ o $62.5 \mathrm{ppm}$ siendo esta la concentración mínima inhibitoria (CMI), ya que a partir de esta concentración no hay crecimiento bacteriano.

b) El extracto crudo estandarizado de Scoparia dulcis L. presenta actividad antimicótica con poder fungicida respecto a la levadura Candida albicans, a una concentración de $31.25 \mu \mathrm{g} / \mathrm{ml}$ o $31.25 \mathrm{ppm}$. Ya que desde esta concentración no hay crecimiento bacteriano.

c) El extracto crudo estandarizado de Justicia pectoralis Jacq, no presenta actividad a las concentraciones de estudio del presente trabajo; hay crecimiento visible en todas las cajas rayadas; es decir 31.25 , $62.55,125,250,500,1000$ ppm.

d) El extracto crudo estandarizado de Catharantus roseus (L.) G. Don no presenta actividad antibiótica a estas concentraciones, hay crecimiento visible en todas las cajas rayadas.

\section{Resultado del screening fitoquímico}

Proyecto IQ-CT-073: Selección de germoplasma nativo y domesticación de plantas medicinales. Fundación WONG.

Tabla 2. Scoparia dulcis L.

\begin{tabular}{|l|l|}
\hline FECHA: & Abr-02 \\
& \\
Muestra No & 5 \\
Código agronómico & 2 S85K2 \\
Código laboratorio & 5 SE1 AFC \\
Especie & $\mathrm{S}$ \\
& \\
COMPUESTO & \\
& \\
Alcaloides & $\mathrm{D}, \mathrm{M}, \mathrm{W}(++),(+),(++)$ \\
Taninos & $(++)$ \\
Flavonoides & $(-)$ \\
Glucósidos cardiotónicos & $(++)$ \\
Saponinas & $(-)$ \\
Cumarinas & $(-)$ \\
Glucósidos cianogenéticos & $(-)$ \\
Antraquinonas & $(-)$ \\
\hline
\end{tabular}

Tabla 3. Justicia pectoralis Jacq.

\begin{tabular}{|l|l|}
\hline FECHA: & May-02 \\
Muestra N & 12 \\
Código agronómico & 3J142N1 \\
Código laboratorio & 12JE1 AFC \\
Especie & $\mathrm{J}$ \\
& \\
COMPUESTO & \\
& \\
Alcaloides & $\mathrm{D}, \mathrm{M}, \mathrm{W}(++),(+),(+++)$ \\
Taninos & $(+)$ \\
Flavonoides & $(+-)$ \\
Glicósidos cardiotónicos & $(+)$ \\
Saponinas & $(-)$ \\
Cumarinas & $(-)$ \\
Glucósidos cianogenéticos & $(-)$ \\
Antraquinonas & $(-)$ \\
Sesquiterpenlactonas & $(-)$ \\
Esteroides & $(+++)$ \\
\hline
\end{tabular}

Tabla 4. Catharanthus roseus (L.) G. Don.

\begin{tabular}{|l|l|}
\hline FECHA: & Abr-02 \\
Muestra N & 1 \\
Código agronómico & $1 \mathrm{C} 46 \mathrm{~N} 2$ \\
Código laboratorio & $1 \mathrm{CE} 1 \mathrm{AFC}$ \\
Especie & $\mathrm{C}$ \\
& \\
COMPUESTO & \\
& \\
Alcaloides & $\mathrm{D}, \mathrm{M}, \mathrm{W}(+++),(+),(+++)$ \\
Taninos & $(+)$ \\
Flavonoides & $(-)$ \\
Glicósidos cardiotónicos & $(+)$ \\
Saponinas & $(-)$ \\
Cumarinas & $(-)$ \\
Glicósidos cianogeneticos & $(-)$ \\
Antraquinonas & $(-)$ \\
Sesquiterpenlactonas & $(-)$ \\
Esteroides & $(+++)$ \\
\hline
\end{tabular}

Tabla 5. Resultados de Actividad Antibacteriana de las plantas en estudio: Catharanthus roseus (L.) G. Don, Justicia Pectoralis Jacq., Scoparia dulcis L., que fueron domesticadas en el Centro Científico Río Palenque y la investigación microbiológica se realizó en el Laboratorio de Microbiología de la Facultad de Ciencias Químicas UCE. 
(+) Resistencia

\begin{tabular}{|c|c|c|c|c|c|c|c|c|c|c|c|c|c|c|c|c|c|c|c|c|c|c|c|c|}
\hline & & & & & & & & & & & & & & & & & & & \multicolumn{6}{|c|}{ control } \\
\hline & \multicolumn{6}{|c|}{ Scoparia dulcis L. } & \multicolumn{6}{|c|}{ Justicia pectoralis Jacq. } & \multicolumn{6}{|c|}{ Catharantus roseus L. G. Don } & \multicolumn{6}{|c|}{ Sulfato de Estreptomicina } \\
\hline Salmonella & + & + & + & + & + & + & + & + & + & + & + & + & + & + & + & + & + & + & - & - & - & - & - & - \\
\hline Escherichia coli & + & + & + & + & + & + & + & + & + & + & + & + & + & + & + & + & + & + & - & - & - & - & - & - \\
\hline Proteus & + & + & + & + & + & + & + & + & + & + & + & + & + & + & + & + & + & + & - & - & - & - & - & - \\
\hline Klebsiella & + & + & + & + & + & + & + & + & + & + & + & + & + & + & + & + & + & + & - & - & - & - & - & - \\
\hline Staphylococus aureus & + & + & + & + & + & + & + & + & + & + & + & + & + & + & + & + & + & + & - & - & - & - & - & - \\
\hline Pseudomona aeruginosa & - & - & - & - & - & + & + & + & + & + & + & + & + & + & + & + & + & + & - & - & - & - & - & - \\
\hline Candida albicans & - & - & - & - & - & - & + & + & + & + & + & + & + & + & + & + & + & + & - & - & - & - & - & - \\
\hline concentración (ppm) & 1000 & 500 & 250 & 125 & 62,5 & 31,3 & 1000 & 500 & 250 & 125 & 62,5 & 31,3 & 1000 & 500 & 250 & 125 & 62,5 & 31,3 & 1000 & 500 & 250 & 125 & 62,5 & 31,3 \\
\hline
\end{tabular}

\section{Discución}

\section{Scoparia dulcis L.}

\section{Etnobotánica y etnomédica.}

En Costa Rica, la decocción preparada con esta planta se emplea como estomáquico, diurético y contra las fiebres intermitentes. Se usa contra la blenorragia y en desórdenes menstruales.

En Panamá, se usa como diurético y para disolver cálculos renales y cefalalgia. Para las dos primeras afecciones, se prepara una infusión de las raíces y se toma como agua de pasto (tres a cinco veces durante 15 días). Para el dolor de cabeza, se toma la infusión de dos o tres plantas frescas, y también se coloca la planta machacada sobre la frente, seguida de masaje. (Gupta, 1995)

En Colombia García-Barriga, 1974, señaló que esta especie, sirve como febrífugo y para el paludismo. En Ecuador como anticonceptivo. La planta entera en Brasil, se usa como antidiabética y expectorante. En Perú, se considera mucolítica, astringente y febrífuga; además, se usa en las ceremonias rituales chamanísticas.

En Paraguay, la infusión o decocción de las partes aéreas de la planta se utiliza para combatir la micciones dolorosas, la frialdad y la vaginitis. Una maceración en agua fría de la parte aérea de la planta es utilizada para tratar las urticarias. El zumo de la planta se emplea contra parásitos de la piel. El cocimiento de la raíz al 10 por mil se emplea en afecciones gastrointestinales, digestiones lentas, flatulencias, cólicos y constipaciones. Se le atribuyen además, propiedades diuréticas y depurativas (González, 1992).

Es ampliamente usada en la América Latina como febrífugo, depurativo, antidiabético y tónico, también se usa como substituto de la ipecacuana para inducir el vómito; en Haití se usa para hemorroides.

En África Occidental, la raíz se usa para las enfermedades venéreas y como diurético, estomáquico y depurativo. (Gupta, 1995).Entre los principales productos químicos incluyen también scopadiol, scopaldulciol, scopadulin, el ácido scopadulcic A y B y ácido scoparico A y C que son diterpenos, ácido - 12 - betulínico y glutinol que son triterpenos, sitosterol que es un esteroide, flavonas como vitexin y linarin. (MASUMA, S. y LAZUMA, N. 2011). Con el fin de determinar las propiedades terapéuticas del vegetal han sido realizadas varias investigaciones coincidiendo con los datos expuestos por Das (2001), Masuma (2011) que la teatina contiene terpenos, alcaloides, cumarinas, saponinas, taninos, compuestos fenólicos, flavonoides. Coincidiendo con nuestra investigación en el contenido de alcaloides y taninos.

Badhouse y Cols han encontrado que el infuso y extracto total de A. Splendes tienen actividad antiinflamatoria y antipirética en cobayos y en conejas respectivamente, las que han sido atribuídas a una mezcla de triterpenos y esteroides ( $\beta$-sitesterol, glucósido de $\beta$-sitesterol y ácido oleanólico) presentes en extractos 
lipofílicos de la planta (Muñoz, 2004).

De acuerdo a la bibliografía la acción antifúngica de Scoparia dulcis L, posiblemente se deba a la presencia de $\beta$-sitesterol un esteroide presente en Scoparia dulcis L. Coincidiendo con nuestra investigación. Por lo que se recomienda realizar los estudios in vivo del fitofármaco para su industrialización.

El presente estudio pretende dar sustento científico al uso etnomédico de las tres plantas, encontrando que de ellas únicamente Scoparia dulcis L. presentó actividad antimicrobiana contra Pseudomona aeruginosa con una acción bacteriostática, con poder fungicida contra la levadura, Candida albicans.

Cuando una planta revela acción sobre el sistema nervioso central durante el tamizaje farmacológico y presencia de alcaloides en el tamizaje fitoquímico es bastante probable que la acción farmacológica se deba a la fracción alcaloidal. (Nicolai Sharapin, 2000)

De la misma manera, el hecho de evidenciarse la presencia de flavonoides en el "screening fitoquímico y una acción antiinflamatoria en el "screening" farmacológico, esta última puede asociarse a la fracción de flavonoides. (Nicolai Sharapin, 2000) Esta fracción puede ser aislada y sometida a pruebas más específicas.

Se sugiere investigar la acción antiinflamatoria, así como la acción antitumoral de Scoparia dulcis L. previo al screening farmacológico para dar sustento científico al uso etnomédico de la planta en Río Palenque como antitumoral en hinchazones y tumores así como en la provincia de los Ríos.

\section{Justicia pectoralis Jacq.}

\section{Etnobotánica y etnomédica}

En la Amazonia venezolana los "curiosos" o curanderos emplean las hojas de "camaguari" en forma de tabaco en sus ceremonias curativas. En la zona del Orinoco y el Amazonas se le atribuyen a esta especie efectos alucinógenos. (Duke, 1991)

García-Barriga en 1975 informó que los indígenas del Vaupés y el Alto Amazonas utilizan la decocción de toda la planta en las afecciones pulmonares y especialmente en las neumonías; también la consideran como un buen expectorante. Hay una variedad de esta especie Justicia pectoralis Jacq. Variedad stenophylla que es fortificante para lavar los niños, la emplean mucho en forma de decocción para bañar a los niños raquíticos.

Justicia pectoralis Jacq. Variedad stenophylla forma parte de las mezclas de drogas alucinógenas empleadas por varios grupos indígenas de la Amazonía.
Es una planta usada en brujería, especialmente en prácticas que curan. (Martínez et al. 2000)

El uso etnomédico más común en Cuba es como sedante nervioso, también como expectorante, la forma de preparación que se emplea es la decocción de hojas frescas o secas. En el año 1990 esta planta fue incluida en una resolución oficial del Ministerio de Salud Pública de Cuba en la que se autorizaba su uso como sedante por las unidades de salud, se prepara con la hierba seca el extracto fluido, el que mezclado con miel de abejas es usado como sedante.

Como resultado en Cuba se comercializan 7 formas farmacéuticas que son: "tilo" Droga Seca, "tilo" Extracto Fluido, "tilo" Jarabe 1, "tilo" Jarabe 2, "tilo" Jarabe 20\% , "tilo" Melito y "tilo" Polvo. (Martínez et al. 2000)

En Costa Rica, se emplea como tranquilizante ingerido en forma de té en sustitución del tilo europeo. El cocimiento de las hojas se recomienda para catarros bronquiales. En Venezuela, es considerada astringente, expectorante, sedante, antihemorrágica para las vías urinarias y la matriz, se utilizan las hojas en forma de cataplasma para cicatrizar heridas, la raíz en decocción provoca la menstruación, se utiliza para enfermedades del hígado, gota y reumatismo, en forma de infusión. (Martínez, et al, 2000)

Ha sido reportada como afrodisíaca, alucinógena, hemostática, calmante para la excitación nerviosa, sedante y como remedio tradicional de la caquexia, males del pecho, resfriados, tos, fiebre, influenza, náuseas, neumonía, dolores de estómago y heridas. (Martínez et al., 2000).

J. Niño (2008); reporta la presencia de flavonoides en justicia pectoralis jacq. Coincidiendo con nuestro trabajo; en el proyecto: "Actividad antimicrobiana y antioxidante de justicia pectoralis jacq. Y lippia alba cultivada en diferentes pisos térmicos del Tolima-Colombia.

J. Vera; (2007) et al, reporta en Justicia pectoralis Jacq.: Flavonoides, esteroides, taninos, saponinas, cumarinas y lactonas terpénicas, coincidiendo parcialmente con nuestro estudio en los tres primeros analitos fitoquímicos, no reporta alcaloides ni glicósidos cardiotónicos; pudiendo deberse a la variabilidad del terreno y clima.

E. Sánchez et. al (2003) en el tamizaje fitoquímico comprobó la presencia de flavonoides, cumarinas, azúcares reductores, carotenos, triterpenos y/o esteroides. Coincidiendo con nuestro trabajo en: Flavonoides y esteroides, además reportamos alcaloides, taninos y glicósidos cardiotónicos, pudiendo deberse a la variabilidad del terreno y al clima. 
"Entre los principales productos químicos incluyen también scopadiol, scopaldulciol, scopadulin, el ácido scopadulcic A y B y ácido scoparico A y C que son diterpenos, ácido - 12 - betulínico y glutinol que son triterpenos, sitosterol que es un esteroide, flavonas como vitexin y linarin. (MASUMA, S. y LAZUMA, N. 2011) Con el fin de determinar las propiedades terapéuticas del vegetal han sido realizadas varias investigaciones coincidiendo con los datos expuestos por Das (2001), Masuma (2011) que la teatina contiene terpenos, alcaloides, cumarinas, saponinas, taninos, terpenos, compuestos fenólicos, flavonoides." (LLAMUCA, 2014).

\section{Catharanthus roseus (L.) G. Don}

\section{Etnobotánica y etnomédica}

Raíces purgantes, vermífugas (vermicida destructor de gusanos intestinales; SIN: antihelmíntico), depurativas (dícese de lo que se supone capas de purificar los humores. Agente, sustancia o medicamento que tienen esta acción. Se incluyen los purgantes, diuréticos, diaforéticos, etc.), hemostáticas (que cohíbe el flujo de sangre o hemorragia. Agente mecánico, físico o químico que posee esta acción; SIN: hemostático), odontológicas (que se utiliza para el dolor de dientes), hipoglucemiante (que disminuye la cantidad de glucosa contenida en la sangre).

En investigaciones realizadas del extracto crudo de Justicia pectoralis Jacq. En Colombia, en el departamento del Tolima, tiene acción antimicrobiana con respecto a Estafilococos aureus. No coincidiendo con nuestra investigación pudiendo deberse a la variedad del terreno y de las condiciones ambientales en el cual fue cultivado.

La planta dio positiva a la prueba de esteroides, taninos, glicósidos cardiotónicos y alcaloides con mayor intensidad, coincidiendo con los reportes de Charles Beer (1958) y Svodoba (1961) tiene en sus componentes a la Vincristina y Vinblastina, analitos fitoquímicos de uso en la quimioterapia, los cuales pertenecen a la familia de los alcaloides.

\section{Conclusiones}

a) En relación al tamizaje fitoquímico, una vez realizada la investigación se verificó que las tres especies vegetales de estudio, tienen una similitud en cuanto a su contenido químico: alcaloides, taninos, glicósidos cardiotónicos, esteroides; en mayor o menor proporción. Excepto Justicia pectoralis Jacq, que es la única que presenta flavonoides. Por lo que se acepta la hipótesis nula, Ho. "Las tres plantas de estudio tienen igual composición química".

b) En el estudio de la actividad antimicrobiana de las plantas, se comprobó que tienen diferente activi- dad antimicrobiana a diferentes concentraciones de extractos contra los microorganismos utilizados Gram (+) y (-). Por lo que se acepta la hipótesis alternativa $1 \mathrm{Ha}$. "Las tres especies vegetales en estudio tienen diferente actividad bacteriana sobre gérmenes Gram (+) y (-)".

c) Scoparia dulcis L. es la especie de mayor sensibilidad antimicrobiana, siendo activa contra Pseudomona aeruginosa a una concentración de $62,5 \mathrm{ppm}$; siendo esta la concentración mínima inhibitoria (CMI).

d) También presenta actividad antimicótica con poder fungicida contra la levadura Candida albicans en todas las concentraciones. Por lo que se afirma que Scoparia dulcis L. presenta acción bacteriostática sobre Pseudomona aeruginosa, con poder fungicida sobre la levadura Candida albicans.

e) Justicia pectoralis Jacq. No presentó actividad biológica a las concentraciones de estudio frente a los microorganismos seleccionados.

f) Catharanthus roseus (L.) G. Don igual que la anterior especie vegetal no presenta acción biológica a las concentraciones de estudio y contra las cepas seleccionadas.

\section{Recomendaciones}

a) Los resultados del tamizaje fitoquímico constituyen únicamente una orientación y deben interpretarse en conjunto con los resultados del screening farmacológico, por lo que se sugiere realizar dicho screening de las tres plantas, para poder determinar las fracciones químicas o metabolitos secundarios biológicamente activos y ser sometidas a pruebas más específicas.

b) Se recomienda continuar con los estudios in vivo para tratar la candidiasis por medio del extracto estandarizado de Scoparia dulcis L. y el posterior diseño del fitofármaco para el uso etnomédico como bacteriostático contra Pseudomona aeruginosa y fungicida ante la levadura Candida albicans. Desarrollar estudios del mecanismo de acción en cuanto al agente causal de esta patología.

c) Se debería investigar la familia o grupo de antibióticos al cual pertenece el antimicrobiano respectivamente, encontrados en Scoparia dulcis L. y caracterizar su fórmula, pudiendo este ser el responsable del uso etnomédico que se le da en la zona como antiinflamatorio y posible antitumoral.

d) Al presentar las tres plantas alcaloides, en mayor o menor proporción, se sugiere, extraer específicamente las fracciones alcaloidales de las tres plantas y someterlas a la evaluación de la actividad antimi- 
crobiana, concomitante realizar el estudio como: Antiinflamatorios y antitumorales (anticáncer).

\section{Agradecimiento}

Al Dios Altísimo por darme la maravillosa oportunidad de realizar este proyecto.

A la gloriosa Universidad Central del Ecuador y su Facultad de Ciencias Químicas, donde se realizó la evaluación antimicrobiana; a la Fundación Wong y su estación Científica de Río Palenque, donde se realizó la domesticación de las plantas en estudio y el screening fitoquímico..

A la Fundación Wong y al IECE que financiaron este proyecto.

\section{Referencias bibliográficas}

Ander, E. (2001). Guía para preparar monografías. Buenos Aires AR. Lumen Humanitas. Actividad antimicrobiana in vitro de volátiles y no volátiles de Lippia Alba y extractos orgánicos y acuosos de Justicia pectoralis Jacq. Cultivadas en diferentes pisos térmicos del departamento de Tolima, recuperado el 25-jun-2009, disponible en http:// www.utp.edu.co/php/revistas/ScientiaEtTechnica/ docs-FTP/162943345-348.pdf

Brook. (2000). Biología de los microorganismos 8ed. Madrid ES. p 59-60

Brunenton, J. (1999). Pharmacognosy Phytochemistry Medicinal Plants. 2ed. París FR. Lavoisier Publishing 309, 369, 855, 1017, 1019 p.

Cáncer Europa. (2004). Recuperado el 17-jun-2004, disponible en http://www.todocancer.com/NR/ rdonlyres/16EE2037-8959-4500-BD2F-

C3D327BDE81B/0/IncidenciaEuropa.pdf

Catharanthus roseus (L.) G. (2009). Don Wikipedia la enciclopedia libre 17-jul-2009 disponible http:// es.wikipedia.org/wiki/Catharanthus_roseus

Cuellar Rojas, A. (1986). La acción microbiológica inhibitoria de varios extractos del Cantharanthus roseus L. G. Don; Universidad de La Habana.

De la Cueva-Pillajo. (1983). Determinación de la flora herbácea y arbustiva de la Zona de Santo Domingo de los Colorados, Tesis Ingeniería Agronómica. Universidad Central. Quito.

Domínguez, X. (1973). Métodos de investigación Fitoquímica, MX. Limusa.

Goodman, G. (1996). Las bases farmacológicas de la terapéutica. 11ed México, MX. Mc Graw Hill Interamericana p1351.
Granda-Acosta. (1984). Catharantus roseus L. G. Don cultivos tropicales apuntes sobre el cultivo de plantas p491-498.

Gross, et al. (1985). Introducción al estudio de los productos naturales. Buenos Aires, AR. Edit. Eva V. Chesneau. 69, 79, 100, 111, 113,129p.

Koneman, E. et al. (2004). Diagnóstico Microbiológico 5ed. Buenos Aires, AR. Edit. Médica Panamericana 781, 795,796p

La explotación del petróleo en la cuenca amazónica del Ecuador produce una emergencia sanitaria 14may-08 disponible http://publications.paho.org/ spanish/index.cfm

Latorre-Padilla. (1973). Algunos nombres de plantas del Ecuador. Instituto de Ciencias Naturales. Universidad Central. Quito.

Libro el milagro de las plantas.- usos terapéuticos de Scoparia dulcis L. 15-jun-2009 disponible http:// books.google.com.ec/books?

$\mathrm{id}=$ ss3tcgKqh_UC\&pg=PT91\&lpg=PT91\&dq=activ idad+antibacteriana + de + scoparia + dulcis \&source $=-$ bl\&ots=dRQUVz_O3b\&sig=jg8Bg_gPV-gsovhHeBOD5-

oN2A8\&hl=es\&ei=_BxASvDxPM6ntgfh6yfAQ\&sa $=X \&$ oi $=$ book_result $\& c t=$ result\&resnum $=$ 2

Martínez, A. (2000) Fundamentos de Agrotecnología de Cultivo de Plantas Medicinales Iberoamericanas. Santa Fe, CO.

Miranda-Cuellar. (2001). Farmacognosia y productos naturales La Habana, CU. Edit. Feux Varela, p164-165.

Moreta, V. (2004). Estudio comparativo de la actividad antibacteriana de algunas especies del género piper, tesis Doc., Quito, Universidad Central del Ecuador, Facultad de Ciencias Químicas p46-50.

Moyón, M. (2014). Determinación de la actividad antifúngica de los extractos del escancel (aerva sanguinolenta), teatina (Scoparia dulcis L), sangorache (Amaranthus hybridus L.) frente a Trichoderma, Penicillium, Aspergillus.

Muñoz, O., Montes, M., \& Wilkomirsky, T. (2004). Plantas medicinales de uso en Chile. Santiago de Chile: Maval Ltda.

Narváez, I. (2004). Derecho ambiental y sociología ambiental 1ed. Quito, EC. Edit. Librería Jurídica Cevallos. 
Navarrete, A. (2013). Estudio Fitoquímico y de caracterización de los Extractos Obtenidos de Catharanthus roseus. Revista Latinoamericana de Química, 302.

Osorio, J. N. (2007). Vicerrectoría de Investigaciones, Innovación y Extensión. Obtenido de Universidad Tecnológica de Pereira: http:// www.utp.edu.co/vicerrectoria/investigaciones/ investigaciones/DetallesProyecto/725

Proyecto IQ-CT-073: Selección de germoplasma nativo y domesticación de plantas medicinales. Fundación WONG.

Reascos, V. (2007). Variación de la concentración de marcadores químicos de Justicia pectoralis Jacq., Catharanthus Roseus y Scoparia Dulcis, en función de la tasa de crecimiento de las plantas, tesis Esp., Quito, Universidad Central del Ecuador, Facultad de Ciencias Químicas 33,32,46,49,50,58,59,60p.

Remington, A. (1987). Farmacia. 17ed. Buenos Aires, AR. Edit. Médica Panamericana S.A. p1185

Rogi, J. (1988). Plantas medicinales, aromáticas o venenosas de Cuba. La Habana CU. Edit. Científico Técnica, p1125.

Russells, H. (2004). Pharmaceutical Microbiology. 7ed. Gosport, RU Edit. Blackwell Science Ltd. p13-1.

Sánchez Govín, E., Fuentes Hernández, L., Chávez Figueredo, D., \& Rodríguez Ferrada, C. A. (2003). Estudio farmacognóstico de Justicia pectoralis Jacq. Var. Stenophylla Leonard. Rev. Cubana Plant Med. v.8 n.3 Ciudad de la Habana.

Sánchez, C. (1995). Manual de Técnicas de Investigación, CYTED.

Sharapin, N. et al, (2000). Fundamentos de Tecnología de Productos Fitoterapéuticos Sub Programa X CYTED, 1ed. Santa Fe de Bogotá. CO. Edit.: Quebecor- Impreandes p. 198-203

Vera, J. R., Pastrana, P. F., Fernández, K., \& Viña, A. (2007). Actividad Antimicrobiana in vitro de volátiles y no volátiles de Lippia Alba y extractos orgánicos y acuoso de Justicia Pectoralis cultivadas en diferentes pisos térmicos del Departamento del Tolima. Scientia et Technica Año XIII, 345-348.

Vicaria (2009). Recuperado el 01-agost-2009 disponible en http:// www.sld.cu/fitomed/vic.html

Villacrés, V. et al, (1995). Bioactividad de plantas Amazónicas. 1ed. Quito, EC. Edit. Abya-Yala. P60-68.

Vinblastina (2009). Wikipedia la enciclopedia libre recuperado el 11-ene-2009 disponible http:// es.wikipedia.org/wiki/Vinblastina

\section{MOVILIDAD ESTUDIANTIL}

La formación y transmisión de conocimientos y experiencias en la FIGEMPA, permite que en la actualidad sus estudiantes puedan acceder a diversas oportunidades de intercambio estudiantil, de lo cual esperamos sea una práctica diaria y común en nuestra Institución, lo cual se constituye en una alternativa que les permita adquirir experiencias fuera de su Alma Mater, permitiendo que enriquezcan su acervo intelectual y fundamentalmente el humano.

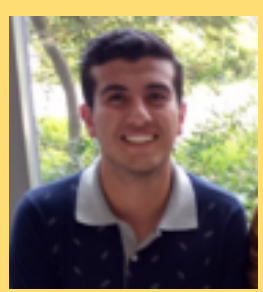

Jorge Proaño, estudiante de 9 semestre de la Carrera de Ingeniería de de Petróleos en un trabajo con otros estudiantes de diferentes países desarrollan un estudio de hidratos de gas y captura, almacenamiento y utilización de $\mathrm{CO} 2$ para mitigación ambiental, que permita encontrar las metodologías más rentables para producir el gas natural atrapado en los hidratos mediante desplazamiento con $\mathrm{CO} 2$ antropogénico en el Laboratorio de Sistemas de Energía y Carbón en el Instituto de Ciencia y Tecnología de Gwangju (GIST) en la República de Corea,.

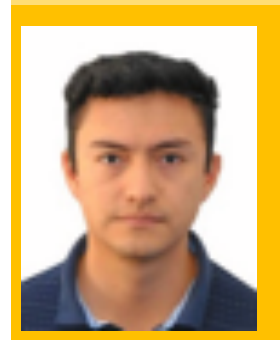

Ing. Joseph Leines, de la promoción 2016 de la Carrera de Ingeniería de de Petróleos, mediante una beca Fullbright, estudiará una Maestría en Ingeniería de Petróleos en Estados Unidos.

"Representar a FIGEMPA y a la Universidad Central mediante una beca Fullbright conlleva una gran responsabilidad, pero al mismo tiempo representa una oportunidad única para contribuir a mi país. Debo este logro principalmente a la excelencia académica de la Universidad Central del Ecuador y a los profesores de la FIGEMPA por su apoyo."

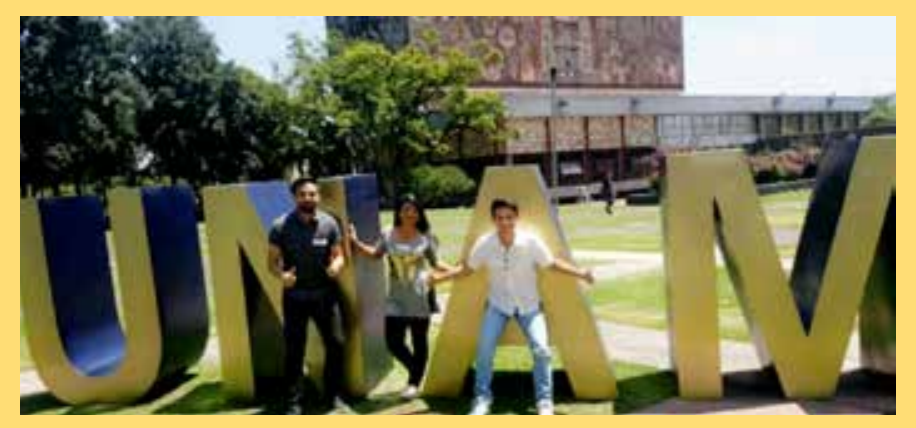

Miguel Corrales, Karla Cárdenas, y Anderson Portilla, estudiantes de $10^{\mathrm{mo}}$ semestre de la Carrera de Ingeniería de Petróleos realizaron el internado en la Unidad de Servicios para la Industria Petrolera en el área de Recuperación Mejorada de la Universidad Nacional Autónoma de México UNAM 